\title{
Vertex and region colourings of planar idempotent divisor graphs of commutative rings.
}

\author{
Mohammed N. Authman", ${ }^{1}$, Husam Q. Mohammad ${ }^{1}$, Nazar H. Shuker ${ }^{1}$ \\ ${ }^{1}$ Department of Mathematics, College of Computer Science and Mathematics, University of Mosul, Mosul, Iraq
}

*Corresponding Author: Mohammed N. Authman

DOI: https://doi.org/10.52866/ijcsm.2022.01.01.008

Received October 2021; Accepted November 2021; Available online January 2022

ABSTRACT: The idempotent divisor graph of a commutative ring $\mathrm{R}$ is a graph with vertices set in $\mathrm{R} *=\mathrm{R}-\{0\}$, and any distinct vertices $\mathrm{x}$ and $\mathrm{y}$ are adjacent if and only if $\mathrm{x} . \mathrm{y}=\mathrm{e}$. For some non-unit idempotent element $e^{2}=e \in R$, it is denoted by $\Pi(\mathrm{R})$. The purpose of this work is to use some properties of ring theory and graph theory to determine the clique number, the chromatic number and the region chromatic number for each planar idempotent divisor graph of the commutative rings. furthermore, we show that the clique number is equal to the chromatic number for any planar idempotent divisor graph. Results indicate that when $\mathrm{F}_{\mathrm{q}}$ and $\mathrm{F}_{\mathrm{p}}^{\alpha}$ are fields of orders $q$ and $p^{\alpha}$, respectively, where $\mathrm{q}=2$ or 3, $\mathrm{p}$ is a prime number and is a positive integer. If ring $R \cong F_{q} \times F_{p}^{\alpha}$, then $\chi(\Pi(R))=\omega(\Pi(R))=\chi^{*}(\Pi(R))=3$.

Keywords: Zero divisor graph; idempotent elements; planar graph and idempotent divisor graph.

\section{INTRODUCTION}

In this work, $\mathrm{R}$ is a finite commutative ring with an identity of $1 \neq 0$, and $\mathrm{Z}(\mathrm{R})$ is a set of all-zero divisors. In 1988 , Beck [1] introduced the relationship between ring and graph theories in the study of the colouring of commutative ring. Later, in 1999, Anderson and Livingston [2], modified the model by studying the zero divisor graph $G(R)$ with vertices $\mathrm{Z}(\mathrm{R})^{*}=\mathrm{Z}(\mathrm{R})-\{0\}$. For $\mathrm{x}_{1}, \mathrm{x}_{2} \in \mathrm{Z}(\mathrm{R})^{*}$ with $\mathrm{x}_{1} \neq \mathrm{x}_{2},\left\{\mathrm{x}_{1}, \mathrm{x}_{2}\right\}$ is an edge in $\Gamma(\mathrm{R})$ if and only if $\mathrm{x}_{1} \cdot \mathrm{x}_{2}=0$. Many authors have since studied this notion (e.g. [3-6]). Moreover, there are many other definitions that connect the two theories of graph and ring (e.g., [7-9]). In 2021, Mohammad and Shuker [10] defined the idempotent divisor graph of commutative ring $R$ with identity $1 \neq 0$. This graph is denoted by $\Pi(R)$, which has vertices set in $R^{*}=R-\{0\}$. For any distinct vertices $\mathrm{x}$ and $\mathrm{y}, \mathrm{x}$ is adjacent to $\mathrm{y}$ if and only if $\mathrm{x} . \mathrm{y}=\mathrm{e}$ for some non-unit idempotent element $\mathrm{e}^{2}=\mathrm{e}$ in $\mathrm{R}$. If $\mathrm{R}$ is a local ring, then the only non-unit idempotent element in $\mathrm{R}$ is zero. They previously assumed that $\mathrm{V}(\Pi(\mathrm{R}))=\mathrm{Z}(\mathrm{R})^{*}$, which means that $\Pi(R)=G(R)$. Furthermore, they presented some fundamental properties of this graph and its connection with $G(R)$, and they also studied the planarity of this graph [10]. In 2021 [11], we studied the size, center and distance between vertices of the idempotent divisor graph of a direct product of two fields, and we determined the general form of this graph when any one of those two fields is a field of order two.

In graph theory, for the connected simple graph $G$, let $H$ be a graph. $G \cup H$ is a graph with $V(G \cup H)=V(G) \cup V(H)$ and $\mathrm{E}(\mathrm{G} \cup \mathrm{H})=\mathrm{E}(\mathrm{G}) \cup \mathrm{E}(\mathrm{H}) . \mathrm{G}+\mathrm{H}$ is a graph with $\mathrm{V}(\mathrm{G} \cup \mathrm{H})=\mathrm{V}(\mathrm{G}) \cup \mathrm{V}(\mathrm{H})$ and $\mathrm{E}(\mathrm{G}+\mathrm{H})=\mathrm{E}(\mathrm{G}) \cup \mathrm{E}(\mathrm{H}) \cup\{\{\mathrm{u}, \mathrm{v}\}: \mathrm{u} \in \mathrm{V}(\mathrm{G}), \mathrm{v} \in \mathrm{V}(\mathrm{H})\}$. Furthermore, let $\mathrm{u}$ and $\mathrm{v}$ be non-adjacent vertices in graph $\mathrm{G}$. Then, $\mathrm{G}+\{\{\mathrm{u}, \mathrm{v}\}\}$ is a graph with $\mathrm{V}(\mathrm{G}+\{\{\mathrm{u}, \mathrm{v}\}\})=\mathrm{V}(\mathrm{G})$ and $\mathrm{E}(\mathrm{G}+\{\{\mathrm{u}, \mathrm{v}\}\})=\mathrm{E}(\mathrm{G}) \cup\{\mathrm{u}, \mathrm{v}\}$. A graph is considered to be complete if each of its two vertices are adjacent. A complete graph of order $\mathrm{n}$ is denoted by $\mathrm{K}_{n} . \mathrm{K}_{1}$ is a graph with only one vertex. A path graph of order $\mathrm{n}$ denoted by $\mathrm{P}_{n}$ is a graph with $\mathrm{V}\left(\mathrm{P}_{n}\right)=\left\{\mathrm{v}_{i}: \mathrm{i}=1,2, \ldots, \mathrm{n}\right\}$ and $\mathrm{E}\left(\mathrm{P}_{n}\right)=\left\{\left\{\mathrm{v}_{j}, \mathrm{v}_{j+1}\right\}: \mathrm{j}=1,2, \ldots, \mathrm{n}-1\right\}$. A cycle graph of order $\mathrm{n}$ denoted by $\mathrm{C}_{n}$ is a graph with $\mathrm{V}\left(\mathrm{C}_{n}\right)=\left\{\mathrm{v}_{i}: \mathrm{i}=1,2, \ldots, \mathrm{n}\right\}$ and $\mathrm{E}\left(\mathrm{C}_{n}\right)=\left\{\left\{\mathrm{v}_{j}, \mathrm{v}_{j+1}\right\}: \mathrm{j}=1,2, \ldots, \mathrm{n}-1\right\} \cup\left\{\left(\mathrm{v}_{1}, \mathrm{v}_{n}\right)\right\}$. A graph $\mathrm{G}$ is b-partite, i.e. $\mathrm{b} \in Z^{+}$, if 
it is possible to partition $\mathrm{V}(\mathrm{G})$ into $\mathrm{b}$ partite subsets $\mathrm{V}_{1}, \mathrm{~V}_{2}, \ldots, \mathrm{V}_{b}$ such that each element of $\mathrm{E}(\mathrm{G})$ joins a vertex of $\mathrm{V}_{i}$ to a vertex of $\mathrm{V}_{j}$ with $\mathrm{i} \neq j$. The task of colouring a graph $\mathrm{G}$ involves assigning colours to the vertices of $\mathrm{G}$, with one colour assigned to each vertex. In this manner, adjacent vertices are assigned with different colours. A colouring in which $\mathrm{k}$ colours are used is called k-colouring. The chromatic number of $\mathrm{G}$ denoted by $\chi(\mathrm{G})$ is defined by the minimum integer $\mathrm{k}$ for which a graph $\mathrm{G}$ is k-colourable. The clique number $\omega(\mathrm{G})$ of a graph $\mathrm{G}$ is the maximum order of each complete subgraphs of $\mathrm{G}$. Clearly, for any graph $\mathrm{G}, \chi(\mathrm{G}) \geq \omega(\mathrm{G})$. More precisely, $\chi(\mathrm{G})$ equals $\omega(\mathrm{G})$ for some special cases of graphs. For example, if $\mathrm{G}$ is a non-empty bipartite graph, then $\chi(\mathrm{G})=\omega(\mathrm{G})=2$. If a graph is embedded in the plane, then it is called a planar graph. Not all planar graph $\mathrm{G}$ satisfies $\chi(\mathrm{G})=\omega(\mathrm{G})$. For example, $\chi\left(\mathrm{C}_{5}\right)=3$, but $\omega\left(\mathrm{C}_{5}\right)=2$. A planar graph $\mathrm{G}$ is said to be an n-region-colourable graph if the regions of $\mathrm{G}$ can be coloured with $\mathrm{n}$ or fewer colours such that adjacent regions are coloured differently. The region chromatic number $\chi *(\mathrm{G})$ of a planar graph $\mathrm{G}$ is the minimum $\mathrm{n}$ for which $\mathrm{G}$ is n-region colourable. For the details, see [12].

In ring theory, we let $\mathrm{R}$ be a finite commutative ring with an identity. $\mathrm{R}$ is considered to be local if it contains a single maximal ideal. Ring $\mathrm{R}$ is a direct product of the rings $\mathrm{R}_{i}$ for $\mathrm{i}=1,2, \ldots, \mathrm{n}$. If $\mathrm{R} \cong \mathrm{R}_{1} \times \mathrm{R}_{2} \times \cdots \times \mathrm{R}_{n}=\left\{\left(\mathrm{r}_{1}, \mathrm{r}_{2}, \ldots, \mathrm{r}_{n}\right): \mathrm{r}_{i} \in \mathrm{R}_{i}\right.$ or if $\mathrm{R}$ is a non-local, then $\mathrm{R}$ is a direct product of the local rings. $\mathrm{F}_{q}$ denotes a field of order $\mathrm{q}$, where $\mathrm{q}$ is a power of prime number. For the details, see [13] and [14].

In this study, we use ring theory and graph theory to determine the clique number, the chromatic number and the region chromatic number for each planar idempotent divisor graph of commutative rings. In Section 2, we discuss the chromatic and clique numbers of all planar idempotent divisor graphs of commutative rings, and we prove these two numbers are equal, i.e. $\chi(\Pi(\mathrm{R}))=\omega(\Pi(\mathrm{R}))$ for any ring $\mathrm{R}$ with planar graph $\Pi(\mathrm{R})$. In Section 3 , we present the general form of $\Pi\left(\mathrm{F}_{3} \times \mathrm{F}_{p^{\alpha}}\right)$ for any prime $\mathrm{p}$ and any positive integer $\alpha$. Moreover, we elaborate the region chromatic numbers for planar idempotent divisor graphs of the commutative rings. Finally, in the last section, we present a table for the values of $\omega(\Pi(\mathrm{R})), \chi(\Pi(\mathrm{R}))$ and $\chi^{*}(\Pi(\mathrm{R}))$ for any commutative ring that has a planar idempotent divisor graph.

\section{VERTEX COLOURING}

In this section, we show that the clique number is equal to the chromatic number for any ring with a planar idempotent divisor graph.

\subsection{CLIQUE NUMBERS AND CHROMATIC NUMBERS OF PLANAR IDEMPOTENT DIVISOR GRAPHS OF LOCAL RINGS}

We begin by presenting the lemma presented in [10].

Lemma 2.1.1. For any local ring $R$, a graph $\Pi(R)$ is planar if and only if $R$ is isomorphic to one of the following rings listed in Table 2.1:

Table 1. Planar idempotent divisor graphs of local rings.

\begin{tabular}{ll}
\hline Ring(s) type & Graph \\
\hline$Z_{4}$ or $F_{2}[Y] /\left(Y^{2}\right)$ & $K_{1}$ \\
$Z_{9}$ or $F_{3}[Y] /\left(Y^{2}\right)$ & $K_{2}$ \\
$F_{2}\left[Y_{1}, Y_{2}\right] /\left(Y_{1}, Y_{2}\right)^{2}, Z_{4}[Y] /(2, Y)^{2}, F_{4}[Y] /\left(Y^{2}\right)$ or $Z_{4}(Y] /\left(Y^{2}+Y+1\right)$ & $K_{3}$ \\
$Z_{8}, Z_{4}[Y] /\left(2 Y, Y^{2}-2\right)$ or $F_{2}[Y] /\left(Y^{3}\right)$ & $K_{1,2}$ \\
$Z_{25}$ or $F_{5}[Y] /\left(Y^{2}\right)$ & $K_{4}$ \\
$Z_{27}, F_{3}[Y] /\left(Y^{3}\right)$ or $Z_{9}[Y] /\left(3 Y, Y^{2} 3\right)$. & $K_{2}+6 K_{1}$ \\
$Z_{16}, F_{2}(Y] /\left(Y^{4}\right), Z_{4}(Y] /\left(2 Y, 2 Y^{2}, Y^{3}-2\right), Z_{4}(Y] /\left(Y^{2}-2 Y-2\right)$, or $Z_{4}(Y] /\left(Y^{2}-2\right)$. & $K_{1}+\left(4 K_{1} \cup\right.$ \\
& $\left.K_{2}\right)$ \\
$Z_{8}(Y] /\left(2 Y, Y^{2}-4\right), Z_{4}(Y] /\left(Y^{2}-2 Y\right), F_{2}\left(Y_{1}, Y_{2}\right] /\left(Y_{1}^{2}, Y_{2}^{2}-Y_{1} Y_{2}\right)$ or & $K_{1}+\left(K_{2} \cup C_{4}\right)$ \\
$Z_{4}\left(Y_{1}, Y_{2}\right] /\left(Y_{1}^{2}, Y_{2}^{2}-Y_{1} Y_{2}, Y_{1} Y_{2}-2,2 Y_{1}, 2 Y_{2}\right)$. & \\
$Z_{4}\left(Y_{1}, Y_{2}\right] /\left(Y_{1}^{2}, Y_{2}^{2}, Y_{1} Y_{2}-2,2 Y_{1}, 2 Y_{2}\right), Z_{4}(Y] /\left(Y^{2}\right)$ or $F_{2}\left(Y_{1}, Y_{2}\right] /\left(Y_{1}^{2}, Y_{2}^{2}\right)$. & $K_{1}+3 K_{2}$ \\
\hline
\end{tabular}

Then, we determine the clique numbers and chromatic numbers of the idempotent divisor graphs of the rings in lemma 2.1.1. Clearly, $\chi\left(K_{i}\right)=i=\omega\left(K_{i}\right)$ for $i=1,2,3,4$. Furthermore, $\chi\left(K_{1,2}\right)=2=\omega\left(K_{1,2}\right)$.

The graphs $K_{2}+6 K_{1}, K_{1}+\left(4 K_{1} \cup K_{2}\right), K_{1}+\left(K_{2} \cup C_{4}\right)$ and $K_{1}+3 K_{2}$ have the following forms:

In the figures, $\chi\left(K_{2}+6 K_{1}\right)=3=\omega\left(K_{2}+6 K_{1}\right), \chi\left(K_{1}+\left(4 K_{1} \cup K_{2}\right)\right)=3=\omega\left(K_{1}+\left(4 K_{1} \cup K_{2}\right)\right), \chi\left(K_{1}+\left(K_{2} \cup C_{4}\right)\right)=3=\omega\left(K_{1}+\right.$ $\left.\left(K_{2} \cup C_{4}\right)\right)$ and $\chi\left(K_{1}+3 K_{2}\right)=3=\omega\left(K_{1}+\left(K_{1}+3 K_{2}\right)\right.$.

Proposition 2.1.2. If $R$ is a local ring and $\Pi(R)$ is a planar graph, then $\chi(\Pi(R))=\omega(\Pi(R))$. 


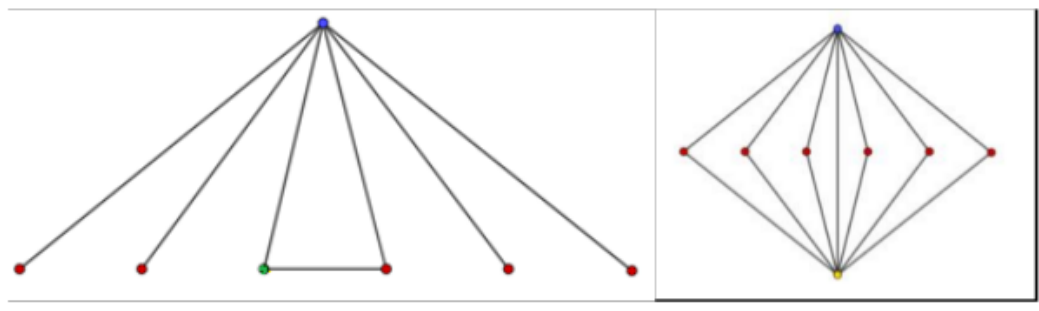

FIGURE 1. (a) $K_{1}+\left(4 K_{1} \cup K_{2}\right)$

(b) $K_{2}+6 K_{1}$

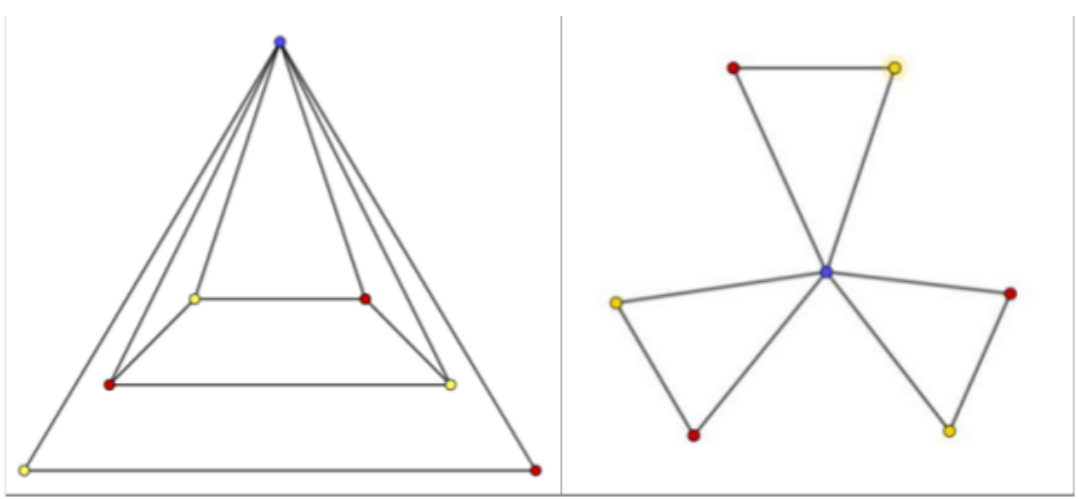

FIGURE 2. (a) $K_{1}+\left(K_{2} \cup C_{4}\right) \quad$ (b) $K_{1}+3 K_{2}$

\subsection{CLIQUE NUMBERS AND CHROMATIC NUMBERS OF PLANAR IDEMPOTENT DIVISOR GRAPHS OF NON-LOCAL RINGS}

We begin this section by presenting the following lemmas:

Lemma 2.2.1. [10]: Let $R$ be a non-local ring. The graph $\Pi(R)$ is planar if and only if $R$ isomorphic to one of the rings. $F_{2} \times F_{q}, F_{3} \times F_{q}, F_{2} \times Z_{4}, F_{2} \times F_{2}[Y] /\left(Y^{2}\right), F_{2} \times Z_{9}$ or $F_{2} \times F_{3}[Y] /\left(Y^{2}\right)$, where $q$ is a power of prime.

Lemma 2.2.2. [10] Let $R \cong K_{1} \times K_{2}$, where $K_{1}$ and $K_{2}$ are fields. Then, $(\Pi(R))=3$.

Firstly, we give the form of the idempotent divisor graphs of $F_{2} \times Z_{4}, F_{2} \times F_{2}[Y] /\left(Y^{2}\right), F_{2} \times Z_{9}$ and $F_{2} \times F_{3}[Y] /\left(Y^{2}\right)$. Clearly, $\Pi\left(F_{2} \times Z_{4}\right) \cong \Pi\left(F_{2} \times F_{2}[Y] /\left(Y^{2}\right) \cong K_{1}+3 K_{2}\right.$. Furthermore, $\Pi\left(F_{2} \times Z_{9}\right) \cong \Pi\left(F_{2} \times F_{3}[Y] /\left(Y^{2}\right)\right.$ has the following form:

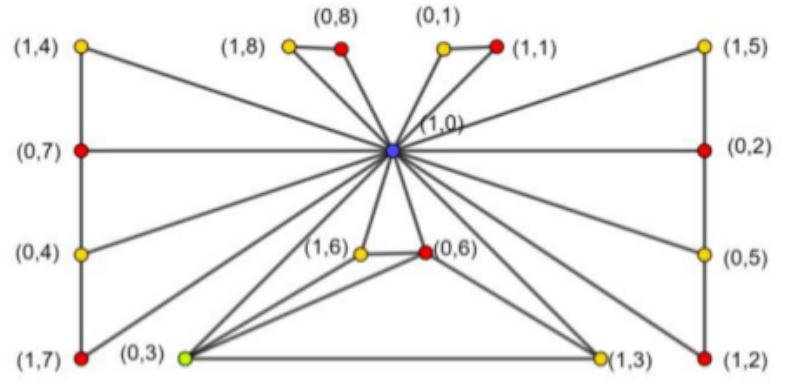

FIGURE 3. $\Pi\left(F_{2} \times Z_{9}\right) \cong \Pi\left(F_{2} \times F_{3}[Y] /\left(Y^{2}\right)\right.$

As shown in the figure, $\chi\left(\Pi\left(\mathrm{F}_{2} \times Z_{4}\right)\right)=\omega\left(\Pi\left(\mathrm{F}_{2} \times Z_{4}\right)\right)=3$, and $\left(\Pi\left(\mathrm{F}_{2} \times Z_{9}\right)\right)=\omega\left(\Pi\left(\mathrm{F}_{2} \times Z_{9}\right)\right)=4$.

To find $\chi\left(\Pi\left(F_{2} \times F_{p^{\alpha}}\right)\right)$ for any prime number $\mathrm{p}$ and any positive integer $\alpha$, we need to derive the following two results, similar to those in [11], for our subsequent results.

Lemma 2.2.3. $[11] \Pi\left(F_{2} \times F_{p^{\alpha}}\right) \cong K_{1}+\left(2 K_{2} \cup\left(\bigcup_{i=1}^{p^{\alpha}-3} P_{4}\right)\right)$, where $p$ is a prime number greater than $2, \alpha \in Z^{+}$. 
Lemma 2.2.4. [11] $\Pi\left(F_{2} \times F_{p^{\alpha}}\right) \cong K_{1}+\left(K_{2} \cup\left(\bigcup_{i=1}^{p^{\alpha-1}-1} P_{4}\right)\right)$, where $p=2, \alpha \in Z^{+}$.

Theorem 2.2.5. $\chi\left(\Pi\left(F_{2} \times F_{p^{\alpha}}\right)\right)=\left(\Pi\left(F_{2} \times F_{p^{\alpha}}\right)\right)=3$ for any prime $p$ and any positive integer $\alpha$.

Proof. According to Lemma 2.2.2, we have $\left(\Pi\left(F_{2} \times F_{p^{\alpha}}\right)\right)=3$. If $p^{\alpha}=2$ or 3 , then $\Pi\left(F_{2} \times F_{2}\right) \cong \mathrm{K}_{3}$ and $\Pi\left(F_{2} \times F_{3}\right) \cong \mathrm{K}_{1}+2 \mathrm{~K}_{2}$.

Therefore, $\chi\left(\Pi\left(F_{2} \times F_{2}\right)\right)=\chi\left(\Pi\left(F_{2} \times F_{3}\right)\right)=3$. Subsequently, let $p^{\alpha} \geq 4$.

We have the following two cases:

Case 1: If $\mathrm{p}$ is a prime number greater than 2, then from the proof of Lemma 2.2.3 [11], we have $\mathrm{V}\left(\Pi\left(F_{2} \times F_{p^{\alpha}}\right)\right)=$ $F_{2} \times F_{p^{\alpha}}-(0\}=\bigcup_{i=1}^{4} A_{i}$, where $\mathrm{A}_{1}=\{(1,0)\}, \mathrm{A}_{2}=\{(0,1),(1,1)\}, \mathrm{A}_{3}=\{(0,-1),(1,-1)\}$ and $\mathrm{A}_{4}=\bigcup_{i=1}^{\frac{p^{\alpha}-3}{2}} \mathrm{~B}_{i}$ such that $\mathrm{B}_{i}=\left\{\left(0, \mathrm{f}_{i}\right)\right.$, $\left.\left(0, \mathrm{f}_{i}^{-1}\right),\left(1, \mathrm{f}_{i}\right),\left(1, \mathrm{f}_{i}^{-1}\right): \mathrm{f}_{i} \in F_{p^{\alpha}}-\{0,1,-1\}\right\}$ for $\mathrm{i}=1,2, \ldots, \frac{p^{\alpha}-3}{2}$. Thus, $\Pi\left(F_{2} \times F_{p^{\alpha}}\right)$ is

three partite. Let $\mathrm{X}_{1}=\mathrm{A}_{1}, \mathrm{X}_{2}=\{(0,1),(0,-1)\} \cup\left\{\mathrm{U}_{\mathrm{i}=1}^{\frac{\mathrm{p}^{\alpha}-3}{2}}\left\{\left(0, \mathrm{f}_{\mathrm{i}}\right),\left(1, \mathrm{f}_{\mathrm{i}}\right): \mathrm{f}_{\mathrm{i}} \in \mathrm{F}_{\mathrm{p}^{\alpha}}-\left\{0,1,-1, \mathrm{f}_{\mathrm{i}}^{-1}\right\}\right\}\right\}$ and $\mathrm{X}_{3}=$ $\{(1,1),(1,-1)\} \cup\left(\mathrm{A}_{4}-\mathrm{X}_{2}\right)$. Clearly, any two vertices in $\mathrm{X}_{i}$ are not adjacent for any $\mathrm{i}=2,3$. As $\omega\left(\Pi\left(\mathrm{F}_{3} \times \mathrm{F}_{\mathrm{p}^{\alpha}}\right)\right)=$ 3 and $\chi\left(\Pi\left(\mathrm{F}_{2} \times \mathrm{F}_{\mathrm{p}^{\alpha}}\right)\right) \geq \omega\left(\Pi\left(\mathrm{F}_{2} \times \mathrm{F}_{\mathrm{p}^{\alpha}}\right)\right)$, the graph $\Pi\left(\mathrm{F}_{2} \times \mathrm{F}_{\mathrm{p}^{\alpha}}\right)$ is three partite. Therefore, $\chi\left(\Pi\left(\mathrm{F}_{2} \times \mathrm{F}_{\mathrm{p}^{\alpha}}\right)\right)=3$.

Case 2: If $\mathrm{p}=2$, from the proof of Lemma 2.2.4 and by using the same method for the proof of case 1, then we have $\mathrm{V}\left(\Pi\left(F_{2} \times F_{p^{\alpha}}\right)\right)=F_{2} \times F_{2} \alpha-(0\}=\bigcup_{i=1}^{3} A_{i}$, where $\mathrm{A}_{1}=\{(1,0)\}, \mathrm{A}_{2}=\{(0,1),(1,1)\}$ and $\mathrm{A}_{3}=\bigcup_{i=1}^{\frac{p^{\alpha}-2}{2}} \mathrm{~B}_{i}$ such that $\mathrm{B}_{i}=\left\{\left(0, \mathrm{f}_{i}\right)\right.$, $\left.\left(0, \mathrm{f}_{i}^{-1}\right),\left(1, \mathrm{f}_{i}\right),\left(1, \mathrm{f}_{i}^{-1}\right): \mathrm{f}_{i} \in F_{p^{\alpha}}-\{0,1\}\right\}$ for $\mathrm{i}=1,2, \ldots, \frac{p^{\alpha}-2}{2}$. Let $\mathrm{X}_{1}=\mathrm{A}_{1}, \mathrm{X}_{2}=\{(0,1)\} \cup\left\{\bigcup_{i=1}^{\frac{p^{\alpha}-3}{2}}\left\{\left(0, \mathrm{f}_{i}\right),\left(1, \mathrm{f}_{i}\right): \mathrm{f}_{i} \in F_{p^{\alpha}}-\{0,1\right.\right.$, $\left.\left.\left.\mathrm{f}_{i}^{-1}\right\}\right\}\right\}$ and $\mathrm{X}_{3}=\{(1,1)\} \cup\left(\mathrm{A}_{4}-\mathrm{X}_{2}\right)$. Clearly, any two vertices in $\mathrm{X}_{i}$ are not adjacent for any $\mathrm{i}=2,3$. Similar to the scenario in case 1 , the graph $\Pi\left(F_{2} \times F_{p^{\alpha}}\right)$ is three partite. Therefore, $\chi\left(\Pi\left(F_{2} \times F_{p^{\alpha}}\right)\right)=3$ also in case 2 .

Therefore, $\left(\Pi\left(\mathrm{F}_{2} \times \mathrm{F}_{\mathrm{p}^{\alpha}}\right)\right)=\omega\left(\Pi\left(\mathrm{F}_{2} \times \mathrm{F}_{\mathrm{p}^{\alpha}}\right)\right)=3$ for any prime $\mathrm{p}$ and any positive integer $\alpha$.

Example 2.2.6. The graphs $\Pi\left(F_{2} \times F_{4}\right)$ and $\Pi\left(F_{2} \times F_{7}\right)$ have the following forms:

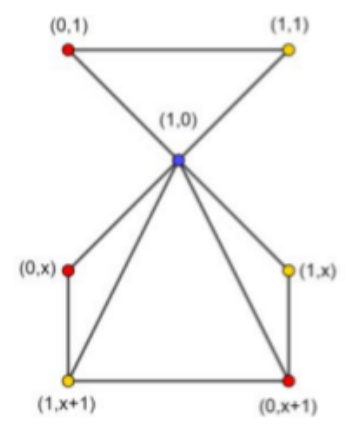

FIGURE 4. (a) $\Pi\left(\mathbf{F}_{2} \times F_{4}\right)$

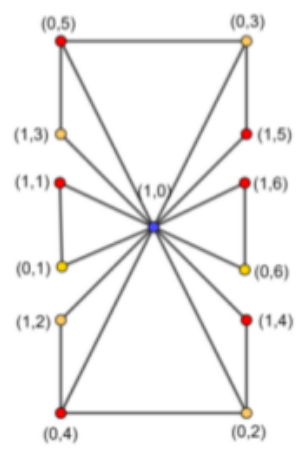

(b) $\Pi\left(\mathbf{F}_{2} \times F_{7}\right)$

Theorem 2.2.7. $\chi\left(\Pi\left(F_{3} \times F_{p^{\alpha}}\right)\right)=\omega\left(\Pi\left(F_{3} \times F_{p^{\alpha}}\right)\right)=3$ for any prime number $p$ and any positive integer $\alpha$.

Proof. According to Lemma 2.2.2, we have $\omega\left(\Pi\left(\mathrm{F}_{3} \times F_{p^{\alpha}}\right)\right)=3$. If $p^{\alpha}=2$, then $\Pi\left(\mathrm{F}_{3} \times F_{p^{\alpha}}\right) \cong \mathrm{K}_{1}+2 \mathrm{~K}_{2}$. Therefore, $\chi$ $\left(\Pi\left(F_{3} \times F_{2}\right)\right)=3$. If $p^{\alpha}=3$, then $\Pi\left(F_{3} \times F_{3}\right)$ has the folowing form:

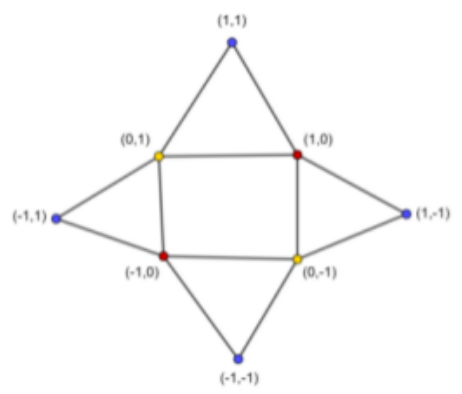

FIGURE 5. $\Pi\left(F_{3} \times F_{3}\right)$ 
Furthermore, $\chi\left(\Pi\left(F_{3} \times F_{3}\right)\right)=3$. Then, we let $p^{\alpha} \geq 4$.

We have the following two cases:

Case 1: If $\mathrm{p}=2$, then for $\mathrm{a} \in 2^{\alpha}, \mathrm{a}=\mathrm{a}^{-1}$ if and only if $\mathrm{a}=1$. Let $\mathrm{R}^{*}=\mathrm{F}_{3} \times F_{p^{\alpha}}-\{0\}=\mathrm{X} \cup Y$ such that $\mathrm{X}=\{(1,0),(-1,0),(1,1),(-$ $1,1),(0,1)\}$ and $\mathrm{Y}=\left\{(0, \mathrm{y}),\left(0, \mathrm{y}^{-1}\right),(1, \mathrm{y}),\left(1, \mathrm{y}^{-1}\right),(-1, \mathrm{y}),\left(-1, \mathrm{y}^{-1}\right): \mathrm{y} \in F_{2^{\alpha}}-\{0,1\}\right\}$. Suppose that $\mathrm{X}_{1}=\{(1,0),(-1,0)\}, \mathrm{X}_{2}=\{(1,1),(-$ $1,1)\} \cup\left\{(0, \mathrm{y}),(1, \mathrm{y}),(-1, \mathrm{y}): \mathrm{y} \in F_{2} \alpha-\left\{0,1, \mathrm{y}^{-1}\right\}\right\}$ and $\mathrm{X}_{3}=\{(0,1)\} \cup\left(Y-\mathrm{X}_{2}\right)$. Clearly, any two vertices in $\mathrm{X}_{i}$ are not adjacent for any $\mathrm{i}=1,2,3$. As $=\omega\left(\pi\left(\mathrm{F}_{3} \times \mathrm{F}_{\mathrm{p}}^{\alpha}\right)\right)=3$ and $\chi\left(\left(\mathrm{F}_{3} \times \mathrm{F}_{\mathrm{p}^{\alpha}}\right)\right) \geq \omega\left(\Pi\left(\mathrm{F}_{3} \times \mathrm{F}_{\mathrm{p}^{\alpha}}\right)\right)$, then the graph $\Pi\left(\mathrm{F}_{3} \times \mathrm{F}_{\mathrm{p}} \alpha\right)$ is three partite. Therefore, $\chi\left(\Pi\left(\mathrm{F}_{3} \times \mathrm{F}_{\mathrm{p}^{\alpha}}\right)\right)=3$.

Case 2: If $\mathrm{p}$ is a prime number greater than 2 , then for $\mathrm{a} \in p^{\alpha}, \mathrm{a}=\mathrm{a}^{-1}$ if and only if $\mathrm{a}= \pm 1$. As a proof of case 1 , $\mathrm{F}_{3} \times F_{p^{\alpha}}-\{0\}=\mathrm{X} \cup \mathrm{Y}$ such that $\mathrm{X}=\{(1,0),(-1,0),(1,1),(-1,1),(0,1),(0,-1),(1,-1),(-1,-1)\}$ and $\mathrm{Y}=\left\{(0, \mathrm{y}),\left(0, \mathrm{y}^{-1}\right),(1, \mathrm{y}),\left(1, \mathrm{y}^{-1}\right),(-\right.$ $\left.1, \mathrm{y}),\left(-1, \mathrm{y}^{-1}\right): \mathrm{y} \in F_{2^{\alpha}}-\{0,1,-1\}\right\}$. Let $\left.\mathrm{X}_{1}=\{(1,0),(-1,0)\}, \mathrm{X}_{2}=\{(1,1),(-1,1)),(1,-1),(-1,-1)\right\} \cup\left\{(0, \mathrm{y}),(1, \mathrm{y}),(-1, \mathrm{y}): \mathrm{y} \in F_{2}^{\alpha}-\{0,1,-\right.$ $\left.\left.1, \mathrm{y}^{-1}\right\}\right\}$ and $\mathrm{X}_{3}=\{(0,1),(0,-1)\} \cup\left(Y-\mathrm{X}_{2}\right)$. Clearly, any two vertices in $\mathrm{X}_{i}$ are not adjacent for any $\mathrm{i}=1,2,3$. The graph $\Pi\left(F_{3} \times F_{p^{\alpha}}\right)$ is three partite. Therefore, $\chi\left(\Pi\left(F_{3} \times F_{p^{\alpha}}\right)\right)=3$ in this case.

Therefore, $\chi\left(\Pi\left(\mathrm{F}_{3} \times \mathrm{F}_{\mathrm{p}^{\alpha}}\right)\right)=\omega\left(\Pi\left(\mathrm{F}_{3} \times \mathrm{F}_{\mathrm{p}^{\alpha}}\right)\right)=3$ for any prime $\mathrm{p}$ and any positive integer $\alpha$.

Example 2.2.8. The graphs $\Pi\left(F_{3} \times F_{4}\right)$ and $\Pi\left(F_{3} \times F_{5}\right)$ have the following forms:

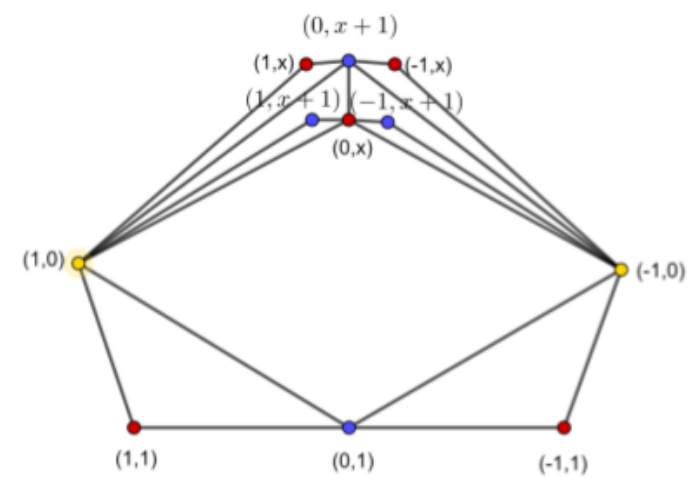

FIGURE 6. (a) $\Pi\left(\mathbf{F}_{3} \times F_{4}\right)$

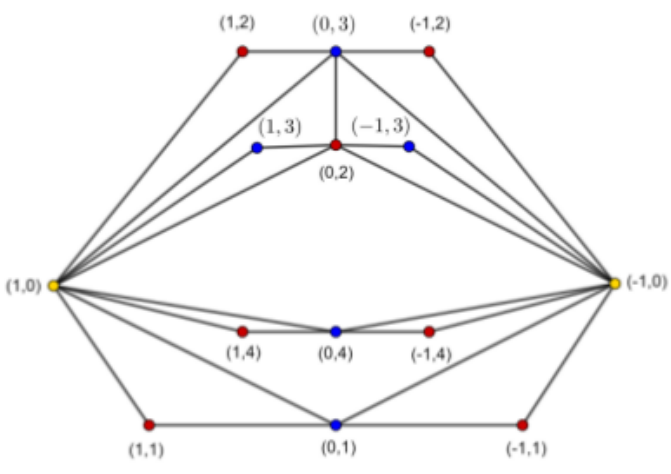

(b) $\Pi\left(F_{3} \times F_{5}\right)$

On the basis of Proposition2.1.2 and Theorems 2.2.5 and 2.2.7, we have the following main result.

Theorem 2.2.9. Let $R$ be any ring with a planar idempotent divisor graph. Then, $\chi(\Pi(R))=\omega(\Pi(R))$.

\section{REGION COLOURING}

In this section, we determine the region chromatic number for planar idempotent divisor graphs of commutative rings.

\subsection{REGION CHROMATIC NUMBERS FOR PLANAR IDEMPOTENT DIVISOR GRAPHS OF LOCAL RINGS}

According to Lemma 2.1.1, we have $\chi^{*}\left(\mathrm{~K}_{i}\right)=\chi^{*}\left(\mathrm{~K}_{1,2}\right)=1$ for $\mathrm{i}=1,2, \chi^{*}\left(\mathrm{~K}_{3}\right)=2$ and $\chi^{*}\left(\mathrm{~K}_{4}\right)=4$. We can colour the regions of all idempotent divisor graphs of local rings as the follows:

As shown in the figure, $\left.\chi^{*}\left(K_{1}+\left(4 K_{1} \cup K_{2}\right)\right)=\chi^{*}\left(K_{1}+3 K_{2}\right)\right)=2$ and $\chi^{*}\left(K_{2}+6 K_{1}\right)=\chi^{*}\left(K_{1}+\left(K_{2} \cup C_{4}\right)\right)=3$.

\subsection{REGION CHROMATIC NUMBERS FOR PLANAR IDEMPOTENT DIVISOR GRAPHS OF NON-LOCAL RINGS}

According to Lemma2.2.1, the idempotent divisor graph of the non-local ring $\mathrm{R}$ is planar if and only if $\mathrm{R} \cong F_{2} \times Z_{4}, F_{2} \times$ $F_{2}[Y] /\left(Y^{2}\right), F_{2} \times Z_{9}, F_{2} \times F_{3}[Y] /\left(Y^{2}\right), F_{2} \times F_{p^{\alpha}}$ or $F_{3} \times F_{p^{\alpha}}$ for any prime number $\mathrm{p}$ and any positive integer $\alpha$. Clearly, $\Pi\left(F_{2} \times Z_{4}\right) \cong \Pi\left(F_{2} \times F_{2}[Y] /\left(Y^{2}\right)\right) \cong K_{1}+3 K_{2}$. Hence, $\chi^{*}\left(\Pi\left(F_{2} \times Z_{4}\right)\right)=2$.

The region colouring of $\Pi\left(F_{2} \times Z_{9}\right)$ and $\Pi\left(F_{2} \times F_{3}[Y] /\left(Y^{2}\right)\right)$ is as follows:

Clearly, $\chi^{*}\left(\Pi\left(F_{2} \times Z_{9}\right)\right)=3$. Subsequently, we find the region chromatic number for $\Pi\left(F_{2} \times F_{p^{\alpha}}\right)$. If $p^{\alpha}=2$ or 3 , then $\Pi\left(F_{2} \times F_{2}\right) \cong \mathrm{K}_{3}$ and $\Pi\left(F_{2} \times F_{3}\right) \cong \mathrm{K}_{1}+2 \mathrm{~K}_{2}$. Therefore $\chi^{*}\left(\Pi\left(F_{2} \times F_{2}\right)\right)=\chi^{*}\left(\Pi\left(F_{2} \times F_{3}\right)\right)=2$. Simialrly, we find $\chi^{*}\left(\Pi\left(F_{2} \times F_{p^{\alpha}}\right)\right)$ for $p^{\alpha} \geq 4$. 


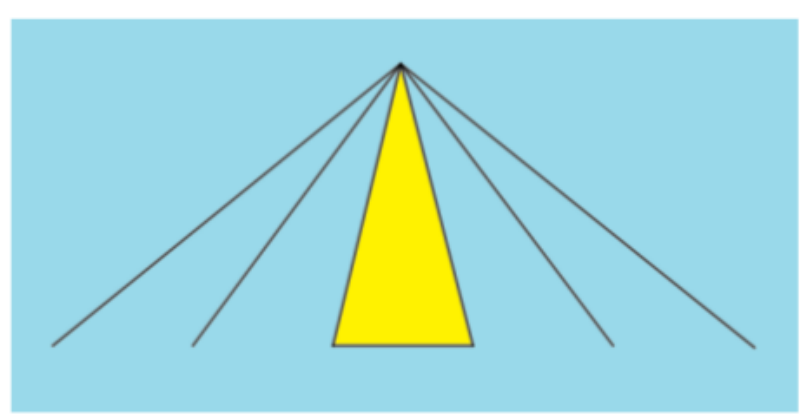

FIGURE 7. (a) $K_{1}+\left(4 K_{1} \cup K_{2}\right)$

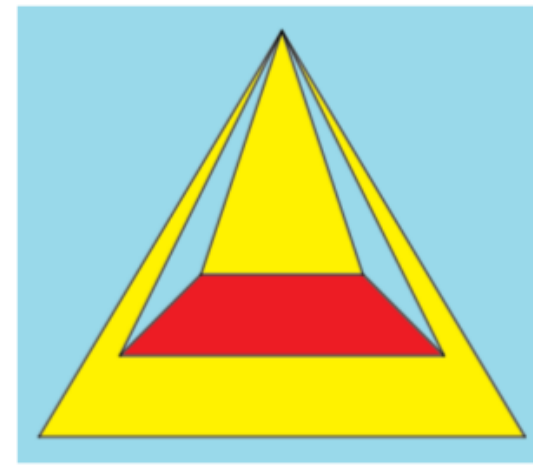

FIGURE 8. (a) $K_{1}+\left(K_{2} \cup C_{4}\right)$

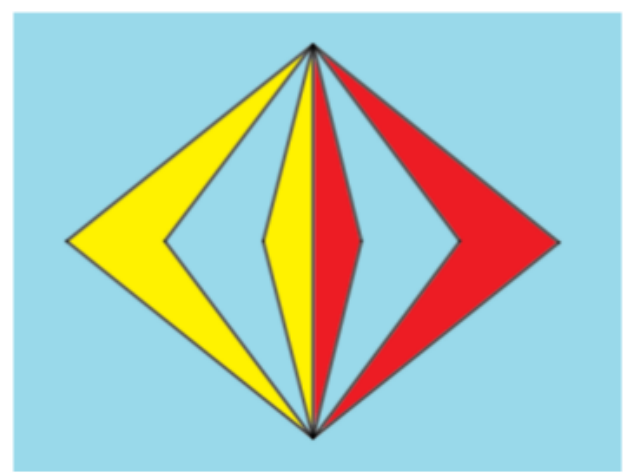

(b) $K_{2}+6 K_{1}$

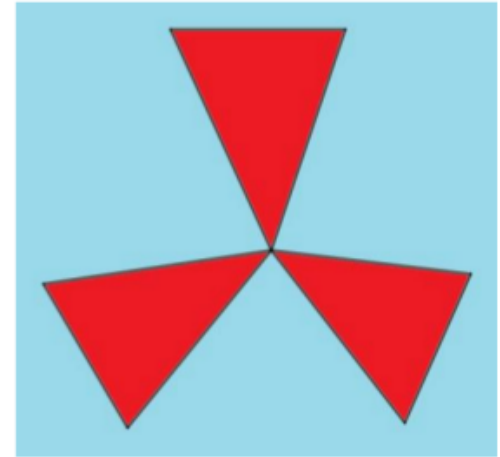

(b) $K_{1}+3 K_{2}$

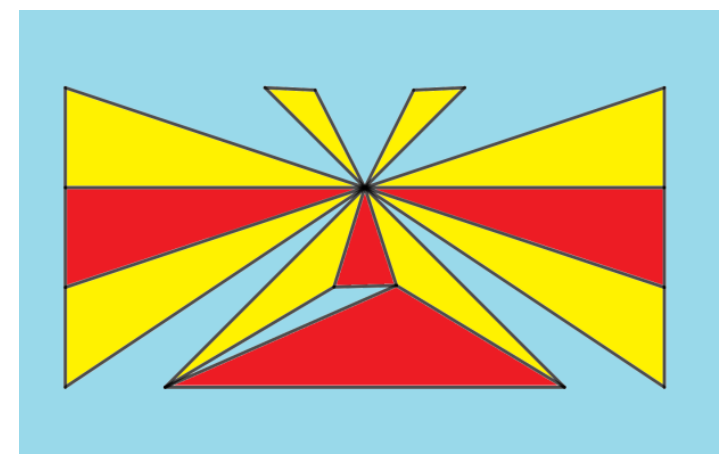

FIGURE 9. $\Pi\left(F_{2} \times Z_{9}\right) \cong \Pi\left(F_{2} \times F_{3}[Y] /\left(Y^{2}\right)\right.$ 
Theorem 3.2.1. $\chi^{*}\left(\Pi\left(F_{2} \times F_{p^{\alpha}}\right)\right)=3$ for any prime number $p$ and any positive integer $\alpha$ with $p^{\alpha} \geq 4$.

Proof. We have the following two cases:

Case 1: If $\mathrm{p}$ is a prime number greater than 2 , according to Lemma 2.2.3 we have $\Pi\left(\mathrm{F}_{2} \times F_{p^{\alpha}}\right) \cong \mathrm{K}_{1}+\left(2 \mathrm{~K}_{2} \cup\left(\bigcup_{i=1}^{\frac{p^{\alpha}-3}{2}} P_{4}\right)\right)$. Clearly, $\chi^{*}\left(\mathrm{~K}_{1}+P_{4}\right)=3$ and $\chi^{*}\left(\mathrm{~K}_{1}+\bigcup_{i=1}^{\frac{p^{\alpha}-3}{2}} P_{4}\right)=3$. Hence, $\chi^{*}\left(2 \mathrm{~K}_{2} \cup\left(\bigcup_{i=1}^{\frac{p^{\alpha}-3}{2}} P_{4}\right)\right)=3$.

Case 2: If $\mathrm{p}=2$, by similarly using the same method of case 1 , we have $\chi *\left(\Pi\left(\mathrm{F}_{2} \times \mathrm{F}_{p} \alpha\right)\right)=3$ in this case. Therefore, $\chi *\left(\Pi\left(\mathrm{F}_{2} \times \mathrm{F}_{p} \alpha\right)\right)=3$.

Example 3.2.2. The colours of the regions of the graph $\Pi\left(F_{2} \times F_{4}\right)$ and $\Pi\left(F_{2} \times F_{7}\right)$ are as follows:

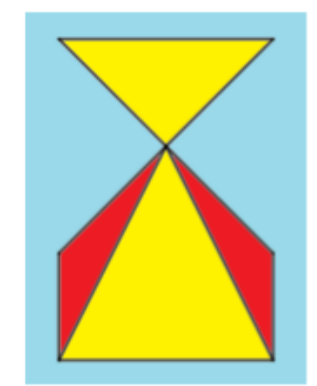

FIGURE 10. (a) $\Pi\left(\mathrm{F}_{2} \times \mathrm{F}_{4}\right)$

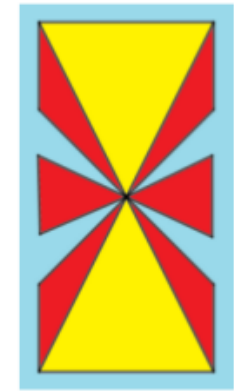

(b) $\Pi\left(\mathrm{F}_{2} \times \mathrm{F}_{7}\right)$

For the graph $\Pi\left(F_{3} \times F_{p^{\alpha}}\right)$, where $p$ is a prime number and $\alpha$ is a positive integer. If $p^{\alpha}=2$, then $\Pi\left(F_{3} \times F_{p^{\alpha}}\right)=\Pi\left(F_{3} \times F_{2}\right) \cong$ $K_{1}+2 K_{2}$. Therefore, $\chi^{*}\left(\Pi\left(F_{3} \times F_{2}\right)\right)=2$. If $p^{\alpha}=3$, then the colour of the regions of the graph $\Pi\left(F_{3} x F_{3}\right)$ is as follows:

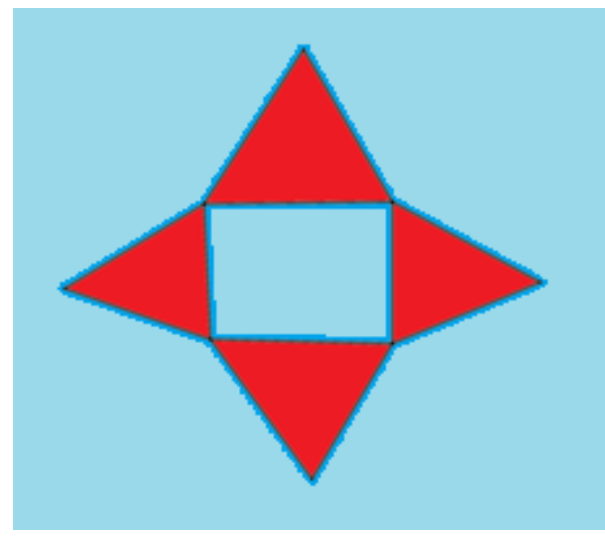

FIGURE 11. $\Pi\left(F_{3} \times F_{3}\right)$

Therefore, $\chi^{*}\left(\Pi\left(F_{3} \times F_{3}\right)\right)=2$.

Theorem 3.2.3. $\chi^{*}\left(\Pi\left(F_{3} \times F_{p^{\alpha}}\right)\right)=3$ for any prime number $p$ and any positive integer $\alpha$ with $p^{\alpha} \geq 4$.

Proof. We have the following two cases:

Case 1: If $\mathrm{p}=2$, according to Theorem 2.2.7, we have $\mathrm{F}_{3} \times F_{p^{\alpha}}-\{0\}=\mathrm{X} \cup Y$ such that $\mathrm{X}=\{(1,0),(-1,0),(1,1),(-1,1),(0,1)\}$ and $\mathrm{Y}=\left\{(0, \mathrm{y}),\left(0, \mathrm{y}^{-1}\right),(1, \mathrm{y}),\left(1, \mathrm{y}^{-1}\right),(-1, \mathrm{y}),\left(-1, \mathrm{y}^{-1}\right): \mathrm{y} \in F_{2^{\alpha}}-\{0,1\}\right\}$. Clearly, $\left(Y \mid=3\left(2^{\alpha}\right)-6\right.$. Then, let $F_{2^{\alpha}}^{*}=\left\{\mathrm{a}_{i} \in F_{2^{\alpha}}: \mathrm{a}_{i} \neq 0,1\right.$ nor $a_{i}^{-1}$ for $\left.\mathrm{i}=1,2, \ldots, \frac{2^{\alpha}-2}{2}\right\}$, and let $\mathrm{Y}=\bigcup_{i=1}^{\frac{3\left(2^{\alpha}\right)-6}{6}} A_{i}=\bigcup_{i=1}^{2^{\alpha-1}-1} A_{i}$ such that $\mathrm{A}_{i}=\left\{\left(0, a_{i}\right),\left(0, a_{i}^{-1}\right),\left(1, a_{i}\right),\left(1, a_{i}{ }^{-1}\right)\right.$, $\left(-1, a_{i}\right),\left(-1, a_{i}^{-1}\right): a_{i} \in F_{2^{\alpha}}^{*}$. Clearly, $-\mathrm{K}_{1}+2 \mathrm{~K}_{2}$. For any $\mathrm{i}=1,2, \ldots, 2^{\alpha-1}-1,-$, we have the following form:

The vertex $(1,0)$ is adjacent to the vertices $\left(1, \mathrm{a}_{i}\right),\left(1, a_{i}^{-1}\right),\left(0, \mathrm{a}_{i}\right)$ and $\left(0, a_{i}^{-1}\right)$ of - but not to $\left(-1, \mathrm{a}_{i}\right),\left(-1, a_{i}^{-1}\right)$ for any $\mathrm{i}=1,2, \ldots, 2^{\alpha-1}-1$ in the graph $\Pi\left(\mathrm{F}_{3} \times F_{p^{\alpha}}\right)$. Similarly, the vertex $(-1,0)$ is adjacent only to $\left(-1, \mathrm{a}_{i}\right),\left(-1, a_{i}{ }^{-1}\right)$, $\left(0, \mathrm{a}_{i}\right)$ and $\left(0, a_{i}^{-1}\right)$ of - in the graph $\Pi\left(\mathrm{F}_{3} \times F_{p^{\alpha}}\right)$; otherwise, there is no vertex in $\mathrm{X}$ adjacent to any vertex in - for $\mathrm{i}=1,2, \ldots, 2^{\alpha-1}-1$ in the graph $\Pi\left(\mathrm{F}_{3} \times F_{p^{\alpha}}\right)$. Then, we can express the general form of $\Pi\left(\mathrm{F}_{3} \times F_{2^{\alpha}}\right)$ as follows: 


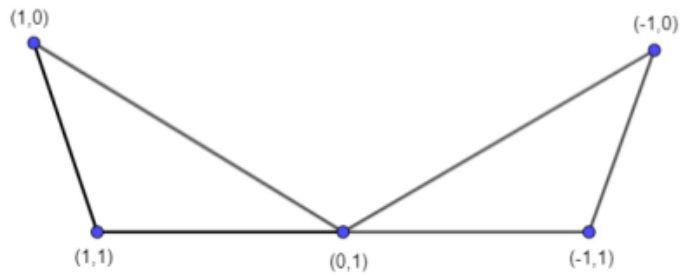

FIGURE 12. (a) $\langle X\rangle$

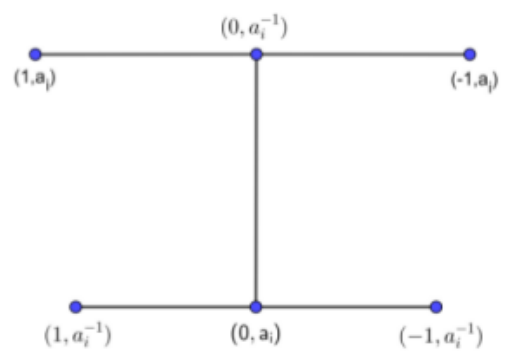

(b) $\left\langle A_{i}\right\rangle$

$\Pi\left(\mathrm{F}_{3} \times F_{2^{\alpha}}\right)=(-)+\mathrm{E}$, where $\mathrm{E}$ is the following subset of $\mathrm{E}\left(\Pi\left(\mathrm{F}_{3} \times F_{p^{\alpha}}\right)\right)$ :

$\mathrm{E}=\left\{\{(\mathrm{j}, 0),(\mathrm{k}, \mathrm{x})\}: \mathrm{j}=1,-1, \mathrm{k}=0, \mathrm{j}, \mathrm{x}=a_{i}, a_{i}^{-1}\right.$ and $\left.\mathrm{i}=1,2, \ldots, 2^{\alpha-1}-1\right\}$.

If $\alpha=2$, then $F_{2^{\alpha}}^{*}=\left\{\mathrm{a}_{1}\right\}$. Hence, $\mathrm{Y}=\mathrm{A}_{1}$ such that $\mathrm{A}_{1}=\left\{\left(0, a_{1}\right),\left(0, a_{1}^{-1}\right),\left(1, a_{1}\right),\left(1, a_{1}{ }^{-1}\right),\left(-1, a_{1}\right),\left(-1, a_{1}{ }^{-1}\right)\right\}$. Thus, $\mathrm{F}_{3} \times F_{p^{\alpha}}=\mathrm{X} \cup \mathrm{A}_{1}$. Furthermore, $\Pi\left(\mathrm{F}_{3} \times F_{2} \alpha\right)=\Pi\left(\mathrm{F}_{3} \times F_{4}\right)=(-)+\left\{\left\{(1,0),\left(0, a_{1}\right)\right\},\left\{(1,0),\left(0, a_{1}^{-1}\right)\right\},\left\{(1,0),\left(1, a_{1}\right)\right\}\right.$,

$\left.\left\{(1,0),\left(1, a_{1}^{-1}\right)\right\},\left\{(-1,0),\left(0, a_{1}\right)\right\},\left\{(-1,0),\left(0, a_{1}^{-1}\right)\right\},\left\{(-1,0),\left(-1, a_{1}\right)\right\},\left\{(-1,0),\left(-1, a_{1}^{-1}\right)\right\}\right\}$. The corresponding forms are as follows:

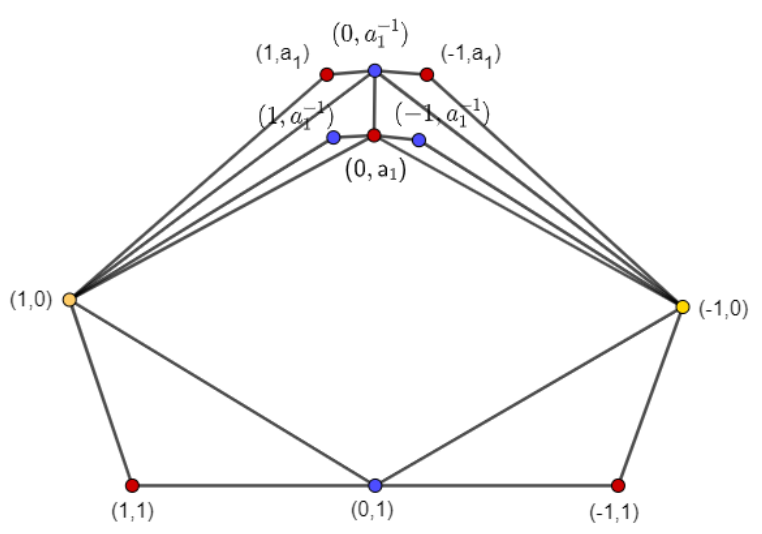

FIGURE 13. $\Pi\left(\mathbf{F}_{3} \times F_{4}\right)$

$\Pi\left(\mathrm{F}_{3} \times F_{2^{2}}\right)$ has the following colours for the regions:

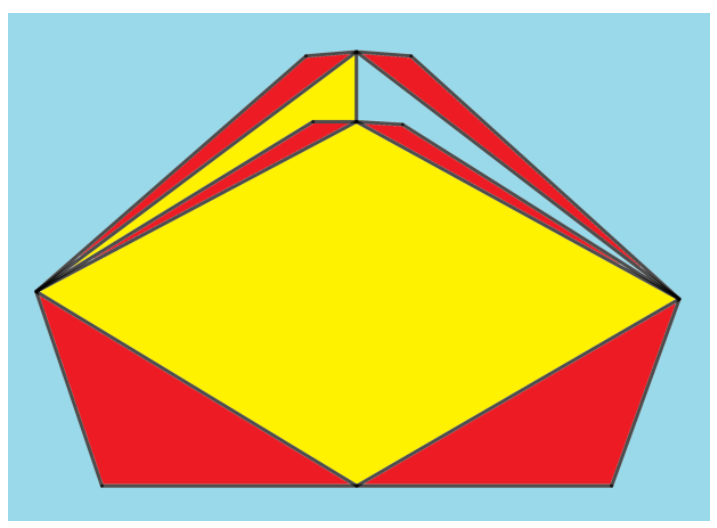

FIGURE 14. Region colouring of $\Pi\left(\mathbf{F}_{3} \times F_{4}\right)$

As shown in the figure, $\chi^{*}\left(\Pi\left(\mathrm{F}_{2} \times F_{4}\right)\right)=3$. 
Let $\alpha=3$; then, $F_{2 \alpha}^{*}=\left\{\mathrm{a}_{1}, \mathrm{a}_{2}, \mathrm{a}_{3}\right\}$. Hence, $\mathrm{Y}=\mathrm{A}_{1} \cup \mathrm{A}_{2} \cup \mathrm{A}_{3}$ such that $\mathrm{A}_{i}=\left\{\left(0, a_{i}\right),\left(0, a_{i}{ }^{-1}\right),\left(1, a_{i}\right)\right.$, $\left.\left(1, a_{i}{ }^{-1}\right),\left(-1, a_{i}\right),\left(-1, a_{i}^{-1}\right)\right\}$ for $\mathrm{i}=1,2,3$. Thus, $\mathrm{F}_{3} \times F_{p^{\alpha}}=\mathrm{X} \cup \mathrm{A}_{1} \cup \mathrm{A}_{2} \cup \mathrm{A}_{3}$, Moreover, $\Pi\left(\mathrm{F}_{3} \times F_{2} \alpha\right)=\Pi\left(\mathrm{F}_{3} \times F_{8}\right)=(-\{\{(\mathrm{j}, 0)$, $(\mathrm{k}, \mathrm{x})\}: \mathrm{j}=1,-1, \mathrm{k}=0, \mathrm{j}, \mathrm{x}=a_{i}, a_{i}^{-1}$, in which $\left.\mathrm{i}=1,2,3\right\}$ has the following form:

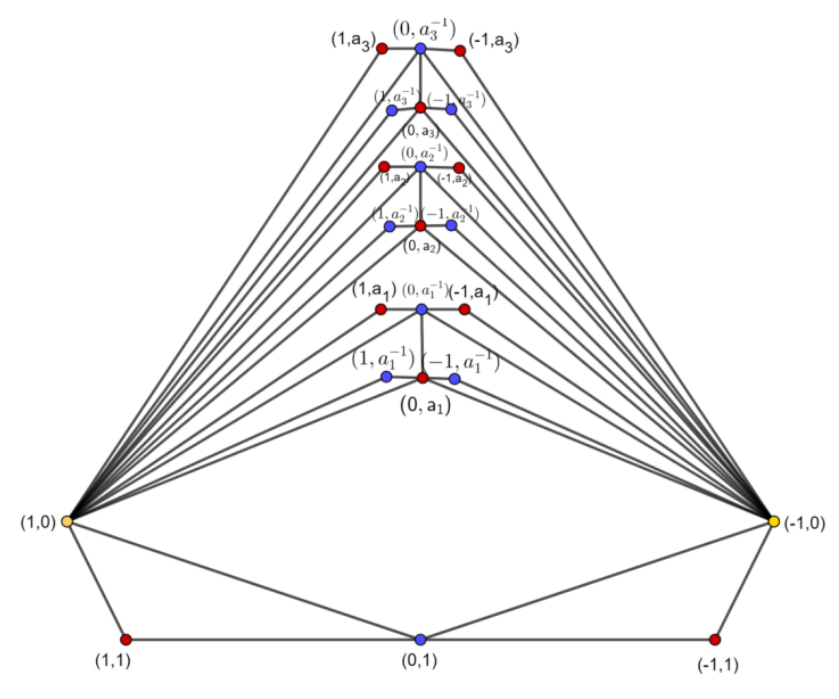

FIGURE 15. $\Pi\left(\mathbf{F}_{3} \times F_{8}\right)$

$\Pi\left(\mathrm{F}_{3} \times F_{2^{3}}\right)$ has the following colours of the regions:

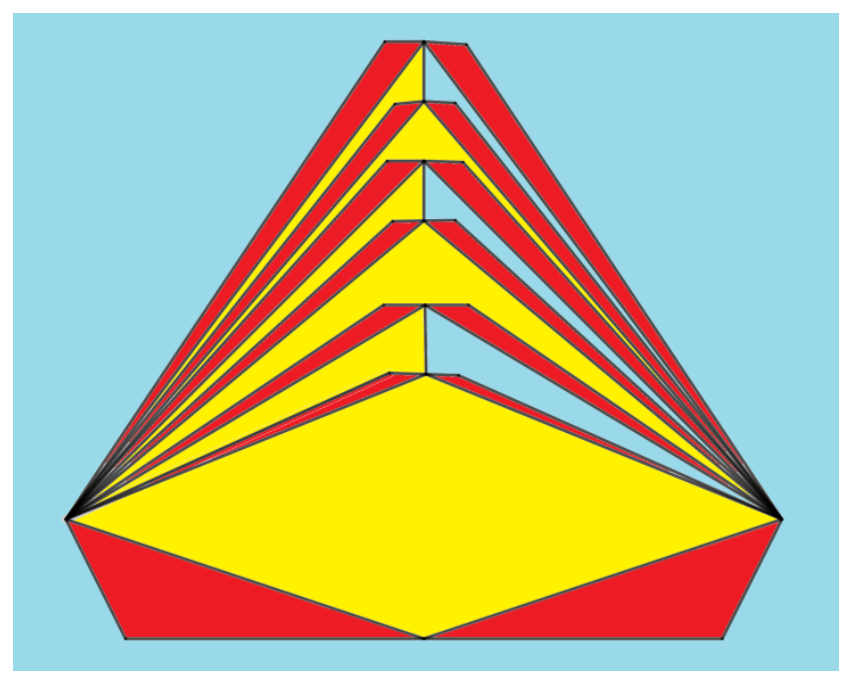

FIGURE 16. Region colouring of $\Pi\left(\mathbf{F}_{3} \times F_{8}\right)$

The figures also show that $\chi^{*}\left(\Pi\left(\mathrm{F}_{3} \times F_{8}\right)\right)=3$.

Similarly, for any $\alpha>3$, we have $\chi^{*}\left(\Pi\left(\mathrm{F}_{3} \times F_{2} \alpha\right)\right)=3$.

Case 2: If $\mathrm{p}$ is a prime number with $\mathrm{p} \neq 2$, by using the same method as a proof of case 1 , then $\mathrm{F}_{3} \times F_{p^{\alpha}}-\{0\}=\mathrm{X} \cup \mathrm{Y}$. $\mathrm{X}=\{(1,0),(-1,0),(1,1),(-1,1),(0,1),(0,-1),(1,-1),(-1,-1)\}$ and $\mathrm{Y}=\bigcup_{i=1}^{\frac{3\left(p^{\alpha}\right)-9}{6}} B_{i}=\bigcup_{i=1}^{\frac{p^{\alpha}-3}{2}} B_{i}$ such that $\mathrm{B}_{i}=\left\{\left(0, b_{i}\right),\left(0, b_{i}^{-1}\right)\right.$, $\left.\left(1, b_{i}\right),\left(1, b_{i}^{-1}\right),\left(-1, b_{i}\right),\left(-1, b_{i}^{-1}\right): b_{i} \in F_{p^{\alpha}}^{*}\right\}$, where $F_{p^{\alpha}}^{*}=\left\{\mathrm{b}_{i} \in F_{2 \alpha}: \mathrm{a}_{i} \neq 0,1,-1\right.$, nor $b_{i}^{-1}$ for $\left.\mathrm{i}=1,2, \ldots, \frac{p^{\alpha}-3}{2}\right\}$. Clearly, - for any $\mathrm{i}=1,2, \ldots, \frac{p^{\alpha}-3}{2}$. Subsequently, - has the following form:

Similar to the scheme in case 1 , the general form of the graph $\Pi\left(\mathrm{F}_{3} \times F_{p^{\alpha}}\right)$ is as follows:

$\Pi\left(\mathrm{F}_{3} \times F_{p^{\alpha}}\right)=(-)+\mathrm{E}$, where $\mathrm{E}$ is given by $\mathrm{E}=\left\{\{(\mathrm{j}, 0),(\mathrm{k}, \mathrm{x})\}: \mathrm{j}=1,-1, \mathrm{k}=0, \mathrm{j}, \mathrm{x}=\mathrm{b}_{\mathrm{i}}, \mathrm{b}_{\mathrm{i}}^{-1}\right.$, and $\left.\mathrm{i}=1,2, \ldots, \frac{\mathrm{p}^{\alpha}-3}{2}\right\}$. Hence, $\chi^{*}\left(\Pi\left(\mathrm{F}_{3} \times \mathrm{F}_{\mathrm{p}^{\alpha}}\right)\right)=3$ in this case. Therefore, $\chi^{*}\left(\Pi\left(\mathrm{F}_{3} \times \mathrm{F}_{\mathrm{p}^{\alpha}}\right)\right)=3$.

Example 3.2.4. The colours of the regions of the graph $\Pi\left(F_{3} \times F_{5}\right)$ is as follows: 


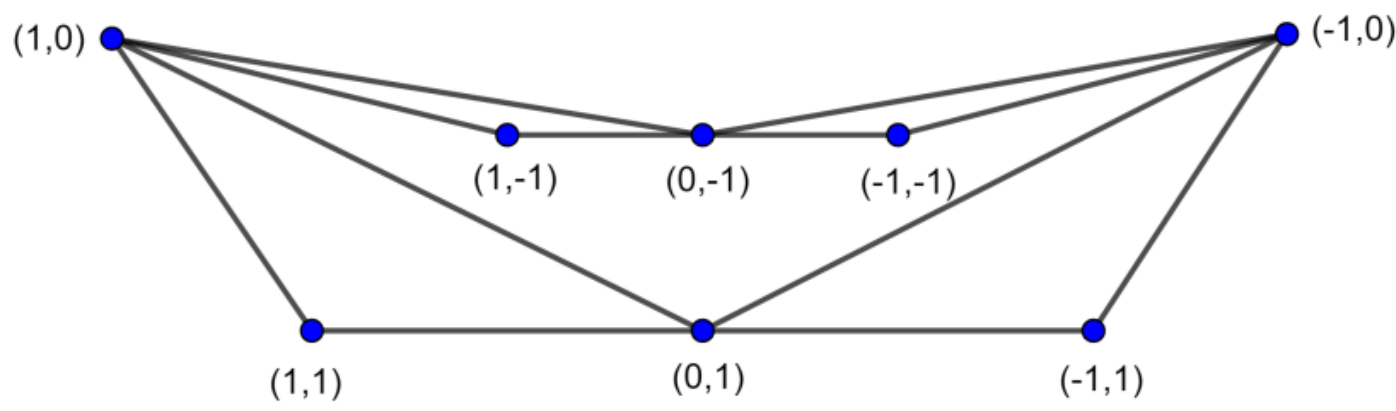

FIGURE 17. $\langle X\rangle$

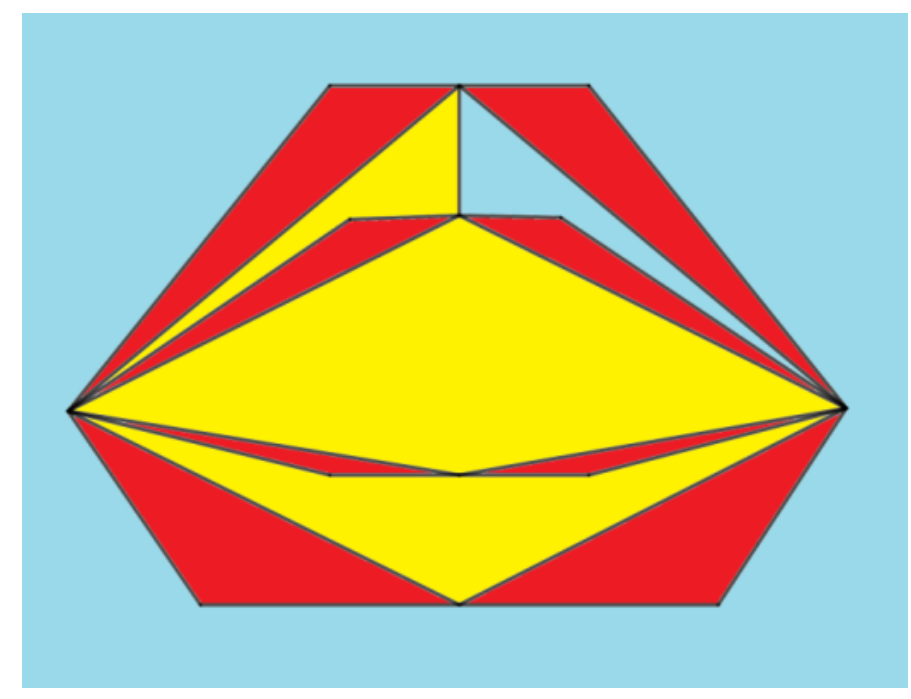

FIGURE 18. $\Pi\left(\mathbf{F}_{3} \times F_{5}\right)$ 


\section{CONCLUSION}

On the basis of the discussions in the last two sections, we have obtained the following table for the clique, the chromatic and the region chromatic numbers for each planar idempotent divisor graph of the commutative rings.

Table 2. Values of $\omega(\Pi(R)), \chi(\Pi(R))$ and $\chi^{*}(\Pi(R))$ for the planar idempotent divisor graphs of commutative rings.

\begin{tabular}{|c|c|c|c|c|c|}
\hline \multirow{2}{*}{$\begin{array}{l}\text { Ring } \mathbf{R} \\
Z_{4} \operatorname{orF}_{2}[Y] /\left(Y^{2}\right)\end{array}$} & \multirow{2}{*}{$\begin{array}{l}\begin{array}{l}\text { Type } \\
\text { of } \mathbf{R}\end{array} \\
\text { Local }\end{array}$} & \multirow{2}{*}{$\begin{array}{l}\text { Order of } \\
\Pi(\mathbf{R}) \\
1\end{array}$} & \multicolumn{3}{|c|}{$\chi(\Pi(R))(\Pi(R)) \chi^{*}(\Pi(R)$} \\
\hline & & & 1 & 1 & 1 \\
\hline$Z_{9}$ or $F_{3}[Y] /\left(Y^{2}\right)$ & Local & 2 & 2 & 2 & 1 \\
\hline$F_{2}\left[Y_{1}, Y_{2}\right] /\left(Y_{1}, Y_{2}\right)^{2}, Z_{4}[Y] /(2, Y)^{2}, F_{4}[Y] /\left(Y^{2}\right)$ or $Z_{4}(Y] /\left(Y^{2}+Y+1\right)$ & Local & 3 & 3 & 3 & 2 \\
\hline$Z_{8}, Z_{4}[Y] /\left(2 Y, Y^{2}-2\right)$ or $F_{2}[Y] /\left(Y^{3}\right)$ & Local & 3 & 2 & 2 & 1 \\
\hline$Z_{25}$ or $F_{5}[Y] /\left(Y^{2}\right)$ & Local & 4 & 4 & 4 & 4 \\
\hline $\begin{array}{l}Z_{16}, F_{2}(Y] /\left(Y^{4}\right), Z_{4}(Y] /\left(2 Y, 2 Y^{2}, Y^{3}-2\right), Z_{4}(Y] /\left(Y^{2}-2 Y-2\right) \text {, or } \\
Z_{4}(Y] /\left(Y^{2}-2\right) .\end{array}$ & Local & 7 & 3 & 3 & 2 \\
\hline $\begin{array}{l}Z_{8}(Y] /\left(2 Y, Y^{2}-4\right), Z_{4}(Y] /\left(Y^{2}-2 Y\right), F_{2}\left(Y_{1}, Y_{2}\right] /\left(Y_{1}^{2}, Y_{2}^{2}-Y_{1} Y_{2}\right) \text { or } \\
Z_{4}\left(Y_{1}, Y_{2}\right] /\left(Y_{1}^{2}, Y_{2}^{2}-Y_{1} Y_{2}, Y_{1} Y_{2}-2,2 Y_{1}, 2 Y_{2}\right) .\end{array}$ & Local & 7 & 3 & 3 & 3 \\
\hline$Z_{27}, F_{3}[Y] /\left(Y^{3}\right)$ or $Z_{9}[Y] /\left(3 Y, Y^{2} 3\right)$ & Local & 8 & 3 & 3 & 3 \\
\hline $\begin{array}{l}Z_{4}\left(Y_{1}, Y_{2}\right] /\left(Y_{1}^{2}, Y_{2}^{2}, Y_{1} Y_{2}-2,2 Y_{1}, 2 Y_{2}\right), Z_{4}(Y] /\left(Y^{2}\right) \\
\text { or } F_{2}\left(Y_{1}, Y_{2}\right] /\left(Y_{1}^{2}, Y_{2}^{2}\right)\end{array}$ & Local & 7 & 3 & 3 & 2 \\
\hline$F_{2} \times Z_{4}$ or $F_{2} \times F_{2}[Y] /\left(Y^{2}\right)$ & $\begin{array}{l}\text { Non- } \\
\text { local }\end{array}$ & 7 & 3 & 3 & 2 \\
\hline$F_{2} \times Z_{9}$ or $F_{2} \times F_{3}[Y] /\left(Y^{2}\right)$ & $\begin{array}{l}\text { Non- } \\
\text { local }\end{array}$ & 17 & 4 & 4 & 3 \\
\hline$F_{2} \times F_{2}$ & $\begin{array}{l}\text { Non- } \\
\text { local }\end{array}$ & 3 & 3 & 3 & 2 \\
\hline$F_{2} \times F_{3}$ & $\begin{array}{l}\text { Non- } \\
\text { local }\end{array}$ & 5 & 3 & 3 & 2 \\
\hline$F_{3} \times F_{3}$ & $\begin{array}{l}\text { Non- } \\
\text { local }\end{array}$ & 8 & 3 & 3 & 2 \\
\hline $\mathrm{F}_{2} \times F_{p^{\alpha}}$, for any prime number $\mathrm{p}$ and any positive integer $\alpha$ with $p^{\alpha} \geq 4$ & $\begin{array}{l}\text { Non- } \\
\text { local }\end{array}$ & $2 p^{\alpha}-1$ & 3 & 3 & 3 \\
\hline $\mathrm{F}_{3} \times F_{p^{\alpha}}$, for any prime number $\mathrm{p}$ and any positive integer $\alpha$ with $p^{\alpha} \geq 4$ & $\begin{array}{l}\text { Non- } \\
\text { local }\end{array}$ & $3 p^{\alpha}-1$ & 3 & 3 & 3 \\
\hline
\end{tabular}

\section{ACKNOWLEDGEMENTS}

The first author thanks the reviewers for their useful suggestions that improved the presentation of this paper.

\section{CONFLICTS OF INTEREST}

The authors declare no conflict of interest.

\section{REFERENCES}

[1] I. Beck. Coloring of commutative rings. Journal of algebra, 1988; vol. 116 no. 1: pp. 208-226.

[2] D.F. Anderson, S. Philip. Livingston. The zero-divisor graph of a commutative ring. Journal of algebra, 1999; vol. 217, no. 2: pp. 434-447.

[3] P.M. Magi, Sr Magie Jose, K. Anjaly. Spectrum of the zero-divisor graph on the ring of integers modulo n. J. Math. Comput. Sci, 2020; vol. 10, no. 5: pp. 1643-1666.

[4] A. Mukhtar, et al. Computing the size of zero divisor graphs. Journal of Information and Optimization Sciences, 2020; vol. 41, no. 4: pp. 855-864.

[5] B.A. Rather, et al., On Laplacian eigenvalues of the zero-divisor graph associated to the ring of integers modulo n, Mathematics 2021 ; vol. 9,no. 5: pp. 482.

[6] Chattopadhyay, Sriparna, Kamal Lochan Patra, and Binod Kumar Sahoo, Laplacian eigenvalues of the zero divisor graph of the ring Zn, Linear Algebra and its Applications, 2020; vol. 584: pp. 267-286.

[7] M. Aijaz, S. Pirzada, Annihilating-ideal graphs of commutative rings, Asian-European Journal of Mathematics, 2020 ; vol.13, no. 07: pp. 2050121.

[8] McNew, Nathan. Counting primitive subsets and other statistics of the divisor graph of $\{1,2, \ldots, n\}$. European Journal of Combinatorics, 2021; vol. 92, no. 1: pp. 103-237.

[9] A. Sharma, K. Dhiren, Nil clean divisor graph, arXiv preprint arXiv, 2019; vol. 1903, no.02287. 
[10] H. Mohammad, N. Shuker, Idempotent divisor graph of commutative ring, Accepted in Iraqi journal of science, 2021.

[11] M. Authman, N. Shuker, H. Mohammad, On idempotent divisor graph of direct product of two fields, Accepted in Journal of Physics: Conference Series, 2021.

[12] Rahman, Md Saidur, Basic graph theory, Springer International Publishing, 2017.

[13] J.A. Beachy, B.D. William, Abstract algebra. Waveland Press, 2019.

[14] E. Aljadeff, et al, Rings with polynomial identities and finite dimensional representations of algebras, vol. 66. American Mathematical Soc., 2020. 